\title{
HUBUNGAN DUKUNGAN KELUARGA DENGAN ACTIVITY DAILY LIVING \\ PADA LANSIA DENGAN KOMPLIKASI HIPERTENSI \\ (Di Desa Banjarejo Kecamatan Rejoso Kabupaten Nganjuk)
}

\author{
Armanila Kerlin Puspandari ${ }^{1}$, Lexy Oktora Wilda ${ }^{2}$, Sefrina Rukmawati ${ }^{3}$ \\ ${ }^{123}$ STIKes Satria Bhakti Nganjuk \\ Email : armanilakerlin2@gmail.com
}

\begin{abstract}
Introduction : Elderly often experience the decline of physiological functions one of them changes in the cardiovascular system so that trigger the occurrence of hypertension. This decine in physiological function leads to a decrease in the ability to perform activity daily living suPch as selfcare.The purpose of this research is to know the Family Support Relationship with Activity Daily Living in Elderly with Hypertension Complication in Banjarejo Village, Rejoso District, Nganjuk Regency.Methode :Research design correlation with cross sectional shortcuts. Implemented on 9 - 12 May 2018 at Posyanduelderly in Banjarejo Village District RejosoNganjuk District with a population of 50 elderly who suffer complications of hypertension. The sampling technique used is total sampling. Total population of 37 and who suffer from hypertension with the number of samples is 37 respondents. Independent variable of family support with questionnaire and dependent variable is daily living activity with Bartel Index. Data analysis using spearmen rank test with significance $\alpha=$ 0,05 .Result :The results showed that 37 respondents were almost half of 15 respondents $(40,5 \%)$ family support with enough category and almost of 20 respondents $(54,1 \%)$ experienced daily living activity with the category of mild dependence. Statistical test results obtained $p$ value $=0,000 \leq \alpha=$ 0.05 with $r=0.598$ so Ha accepted means the level of seedang relationship.Conclusions : Good support in the care of the elderly by always including the patient in every action done every day so that patients do not feel bored. The better the family support the better the patient in fulfilling Activity Daily Living in the elderly with complications of hypertension.
\end{abstract}

Keyword : family support, daily living activity, elderly, and hypertension.

\section{PENDAHULUAN}

$$
\text { Menurut Guntur (2006) proses }
$$

menua adalah suatu proses menghilangnya secara perlahan-lahan kemampuan jaringan untuk memperbaiki dan mempertahankan fungsi normal. Sedangkan menurut Oream (2011) menggambarkan lansia sebagai suatu unit yang juga menghendaki kemandirian dalam mempertahankan hidup, kesehatan, dan kesejahteraan. Lansia juga sering mengalami perubahan fisik akibat proses penuaan diantaranya mengakibatkan perubahan pada sistem kardiovaskuler yang memicu terjadinya hipertensi. Komplikasi yang sering terjadi pada lansia dengan hipertensi adalah serangan jantung, gagal jantung, stroke, aneurisma, masalah ginjal, dan masalah mata. Lansia yang mengalami komplikasi pada hipertensi akan mengakibatkan kesulitan dalam pemenuhan kebutuhan aktivitas sehariharinya. Sedangkan dari studi awal di Desa Banjarejo Kecamatan Rejsoso Kabupaten Nganjuk dari 10 lansia yang menderita hipertensi, sebanyak 3 orang yang 
mengalami penurunan aktivitas sehari-hari diakibatkan stroke, 4 orang mengalami serangan jantung, dan 3 lainnya mengalami gangguan penglihatan.

Menurut data WHO, di seluruh dunia sekitar 972 juta orang atau 26,4\% orang diseluruh dunia mengidap hipertensi, angka ini kemungkinan akan meningkat menjadi $29,2 \%$ di tahun 2015 . Dari 972 juta pengidap hipertensi, 333 juta berada di negara maju dan 639 sisanya berada di negara berkembang, termasuk Indonesia. Dari 3 penyakit yang dialami lansia yaitu hipertensi, DM, dan penyakit paru. Berdasarkan Riset Kesehatan Dasar Tahun 2013 penyakit terbanyak yang dialami lanjut usia adalah hipertensi dengan prevalensi $45,9 \%$ pada usia $55-56$ tahun, $65,74 \%$ dan $63,8 \%$ pada usia $\geq 75$ tahun (Infodatin Kemenkes RI, 2016). Menurut data dari Dinas Kesehatan Kabupaten Nganjuk terdapat 3 desa yang memiliki lansia dengan hipertensi terbanyak yaitu nganjuk, pace, dan rejoso. Dan dari ketiga desa tersebut lansia dengan hipertensi tertinggi berada di daerah kecamatan rejoso. Dan menurut data dari Puskesmas Rejoso untuk Lansia dengan Hipertensi tertinggi berada di wilayah Desa Banjarejo Kecamatan Rejoso Kabupaten Nganjuk dengan jumlah kunjungan rata-rata setiap bulannya 37 orang.
Seiring dengan penuaan lansia seringkali mengalami kemunduran fungsi fisiologis pada organ tubuhnya, salah satunya mengakibatkan perubahan pada sistem kardiovaskuler sehingga memicu terjadinya hipertensi. Kemunduran fungsi fisiologis ini juga dapat menimbulkan penurunan kemampuan untuk melakukan aktivitas sehari-hari seperti perawatan diri yang akhirnya akan berdampak pada ketidakmampuan berfungsi secara optimal baik di rumah maupun di luar rumah. Penurunan kemandirian dalam perawatan diri pada pasien terjadi karena adanya komplikasi pada penderita hipertensi. Kurangnya kemampuan dalam melakukan ADL adalah akibat dari kurangnya kemampuan realitas yang menyebabkan ketidakpedulian terhadap diri dan lingkungannya. Selain itu, kurangnnya dukungan keluarga dalam hal pelatihan ADL kepada anggota keluarga yang mengalami komplikasi pada hipertensi juga merupakan faktor penyebab kurangnnya ADL, seringkali keluarga menyerahkan pengobatan sepenuhnya kepada pihak rumah sakit maupun tenaga kesehatan yang ada di desa.

Pendekatan secara menyeluruh untuk pasien penderita hipertensi sangatlah dibutuhkan untuk kesembuhannya. Selain pendekatan dari sisi medis, dengan pemberian obat-obatan secara rutin, juga dilakukan pendekatan psikososial yaitu 
kemampaun merawat diri. Dengan memberikan aktivitas-aktivitas yang positif, pasien mendapatkan pembelajaran tentang perilaku dan aktivitas sehari-hari melalui Activity Daily Living (ADL), untuk meningkatkan keterampilan merawat diri, sehingga mereka mampu mandiri dalam kesehariannya. Adapun tujuan dari penelitian ini adalah untuk mengetahui sejauh mana dukungan keluarga dengan keefektifan terapi perilaku yaitu Activity Daily Living (ADL) untuk meningkatkan kemampuan pada pasien dengan komplikasi hipertensi untuk merawat diri.

\section{METODE PENELITIAN}

Padaskripsi ini menggunakan desain penelitian korelasi dengan pendekatan cross sectional yaitu metode penelitian yang digunakan sebuah studi dari sekelompok orang pada suatu titik waktu untuk menentukan apakah paparan berkaitan dengan terjadinya penyakit. Karena hasil penyakit dan paparan (misalnya, asupan nutrisi) diukur pada saat yang sama (Nursalam, 2016). Waktu pengambilan data pada tanggal $9-12 \mathrm{Mei}$ 2018 di PosyanduLansia di DesaBanjarejoKecamatanRejoso

Kabupaten Nganjuk.Populasi dalam penelitian ini adalah adalah Semua Lansia dengan Komplikasi Hipertensi di PosyanduLansia di Desa Banjarejo
Kecamatan Rejoso Kabupaten Nganjuk sebanyak 37 lansia.Teknik sampling yang digunakan dalam penelitian ini adalah total sampling, dengan jumlah sampel sebanyak 37 lansia.Variabel independen dalam penelitian ini adalah dukungan keluarga diukur dengan kuesioner dan variabel dependen dalam penelitian ini adalah Activity Daily Livingdiukur dengan indeks Barthel.

Dukungan keluarga terdari dari 4 item, yaitu : dukungan emosional, dukungan pengharapan, dukungan materi, dukungan informasi/pengetahuan. Dan indeks Barthel terdiri dari 10 item,yaitu :pindah kursi/tempat tidur, berjalan/dengan kursi roda, naik tangga, toileting, kontrol bowel, kontrol urin, mandi, berpakaian, kebersihan diri, makan. Interpretasi dukungan keluarga berdasarkan jumlah skor menurut setiadi (2007) yaitu skor 4 (selalu), skor 3 (sering), skor 2 (kadangkadang), skor 1 (tidak pernah). Activity Daily Living responden berdasarkan jumlah skor menurut padila (2013). Jumlah total skor sebagai berikut skor 04(ketergantungan total), skor 5-8 (ketergantungan berat), 9-11 (ketergantungan sedang), skor 12-19 (ketergantungan ringan) skor 20 (mandiri).Data yang telah dikategorikan kemudian dianalisis dengan uji statistik Spearman Rank, $\alpha=0,05$. 


\section{HASIL PENELITIAN}

Tabel 1 Hubungan dukungan keluarga dengan Activity daily living pada Lansia Dengan Komplikasi Hipertensi di Posyandu Lansia di Desa Banjarejo Kecamatan Rejoso Kabupaten Nganjuk pada tanggal 9-12 Mei 2018.

\begin{tabular}{|c|c|c|c|c|c|c|c|c|c|c|c|c|}
\hline \multirow{3}{*}{$\begin{array}{c}\text { Dukungan } \\
\text { keluarga }\end{array}$} & \multicolumn{10}{|c|}{ Activity Daily Living } & \multirow{2}{*}{\multicolumn{2}{|c|}{ Total }} \\
\hline & \multicolumn{2}{|c|}{ Total } & \multicolumn{2}{|c|}{ Berat } & \multicolumn{2}{|c|}{ sedang } & \multicolumn{2}{|c|}{ Ringan } & \multicolumn{2}{|c|}{ Mandiri } & & \\
\hline & $f$ & $\%$ & $\mathrm{~F}$ & $\%$ & $f$ & $\%$ & $f$ & $\%$ & $\mathrm{~F}$ & $\%$ & $\sum$ & $\%$ \\
\hline Baik & 0 & 0 & 0 & 0 & 0 & 0 & 7 & 18,9 & 5 & 13,5 & 12 & 32,4 \\
\hline Cukup & 0 & 0 & 0 & 0 & 0 & 0 & 10 & 27 & 5 & 13,5 & 15 & 40,5 \\
\hline Kurang & 0 & 0 & 0 & 0 & 7 & 18,9 & 3 & 8,1 & 0 & 0 & 10 & 27 \\
\hline \multirow[t]{2}{*}{ Total } & 0 & 0 & 0 & 0 & 7 & 18,9 & 20 & 54,1 & 10 & 27 & 37 & 100 \\
\hline & & & & valu & $=0$ & $\leq$ & 0,05 & & & & & \\
\hline
\end{tabular}

Berdasarkan hasil analisa dengan menggunakan uji statistik spearman rank dengan program SPSS dengan tingkat kemaknaan $\alpha=0,05$ didapatkan $\rho$ value $=$ $0,000 \leq \alpha=0,05$, artinya Ha diterima sehingga ada hubungan dukungan keluarga dengan activity daily living pada Lansia dengan Komplikasi Hipertensi di Posyandu Lansia di Desa Banjarejo Kecamatan Rejoso Kabupaten Nganjuk dan nilai $r$ didapatkan $=0,598$ yang artinya nilai keeratanya sedang..

\section{PEMBAHASAN}

1. Dukungan Keluarga pada Lansia dengan Komplikasi Hipertensi di Posyandu Lansia di Desa Banjarejo Kecamatan Rejoso Kabupaten Nganjuk

Hasil penelitian dari 37 responden, hampir setengahnya yaitu 15 responden (40,5\%) memeiliki dukungan keluarga cukup. Dari 15 responden yang memiliki dukungan keluarga cukup pada komplikasi hipertensi, hampir setengahnya yaitu 13 responden $(35,1 \%)$ memiliki komplikasi masalah mata. Hasil dari uji chisquaredidapatkan $\rho$ value $=0,002$ sehingga dukungan keluarga di pengaruhi oleh komplikasi hipertensi yang diderita oleh lansia. Berdasarkan karakteristik responden yaitu sebagian besar 26 responden $(70,3 \%)$ usia 60-74 tahun. Dari 26 responden $(70,3 \%)$ dalam kategori 6 responden (16,2\%) sebagian kecil dukungan keluarga baik, 11 responden (29,7\%) hampir setengahnya dukungan keluarga cukup, 9 responden (24,3\%) sebagian kecil dukungan keluarga kurang. Dan hampir setengahnya 11 responden (29,7\%) usia 75-90 tahun. Dari 11 responden $(29,7 \%)$ dalam ketegori 6 responden (16,2\%) sebagian kecil dukungan keluarga baik, 4 responden (10,8\%) sebagian kecil dukungan keluarga cukup, 1 responden $(2,7 \%)$ sebagian kecil 
dukungan keluarga kurang. Hasil uji Coeffisiensi contingency di dapatkan 0,040 sehingga dukungan keluarga dipengaruhi oleh usia.

Menurut Purnawan dalam Rahayu (2013), pemberian dukungan keluarga dipengaruhi oleh faktor internal dan faktor eksternal yang keduanya saling berhubungan. Faktor internal berasal dari individu itu sendiri meliputi faktor tahap perkembangan yaiu pemahaman dan respon terhadap perubahan kesehatan yang berbeda-beda pada setiap rentang usia (bayi-lansia). Menurut Mujahidullah (2012), pada hakekatnya panca indra merupakan suatu organ yang tersusun dari jaringan, sedangkan jaringan sendiri merupakan kumpulan sel yang mempunyai fungsi yang sama. Karena mengalami proses penuaan (aging) sel telah mengalami perubahan bentuk maupun komposisi sel tidak normal. Maka secara otomatis fungsi indera pun akan mengalami penurunan. Hal ini dapat dilihat pada orang tua yang secara berangsur-angsur mengalami penurunan kemampuan pendengaran dan mata kurang kesanggupan melihat secara focus objek yang dekat bahkan ada yang menjadi rabun. Semakin lanjut usia seseorang, maka kemampuan fisiknya akan semakin menurun, sehingga dapat mengakibatkan kemunduran pada peran-peran sosialnya (Tumher, 2009).
Hasil penelitian ini sejalan dengan penelitian yang dilakukan oleh Aisyah (2011) tentang analisis faktor-faktor yang mempengaruhi kejadian hipertensi primer di desa Trunuh, Klaten Selatan dimana ditemukan paling banyak pada umur $>45$ tahun yaitu sebanyak 70,2\%. Menurut Osamor (2015), penyakit kronis seperti hipertensi membutuhkan pengobatan seumur hidup. Hal ini merupakan tantangan bagi pasien dan keluarga agar dapat mempertahankan motivasi untuk mematuhi pengobatan selama bertahuntahun. Salah satu cara untuk meningkatkan motivasi adalah melalui dukungan keluarga. (sigit, 2005 dalam sinaga, 2015) mengemukakan keluarga merupakan tempat yang aman dan damai untuk membantu pemulihan dari penyakit. Hasil penelitian ini sejalan dengan penelitian Elfrianti (2016), dimana sebagian besar responden memberikan dukungan cukup terhadap pengaturan pola hidup untuk mencegah terjadinya komplikasi hipertensi.

Berdasarkan fakta dan teori di atas penelitian berpendapat bahwa usia sangat berpengaruh pada hipertensi karena semakin bertambhanya usia, resiko terjadinya hipertensi semakin meningkat, hal ini disebabkan perubahan alami pada jantung, pembuluh darah dimana dinding arteri akan mengalami penebalan karena adanya penumpukan zat kolagen pada 
lapisan otot sehingga pembuluh darah berangsur-angsur menyempit dan manjadi kaku. komplikasi hipertensi juga merupakan salah satu faktor dukungan keluarga. karena secara teori dan fakta berkesinambungan pada pasien hipertensi. Tugas keluarga dalam bidang kesehatan adalah kemampuan mengenal masalah kesehatan, kemampuan merawat anggota keluarga yang sakit, kemampuan memodifikasi lingkungan untuk keluarga yang sakit agar tetap sehat optimal. Peneliti berpendapat bahwa pada lansia yang mengalami komplikasi hipertensi akan mudah terbawa emosi dan merasa dirinya tidak bisa melakukan apapun sehingga lansia akan selalu ketergantungan pada orang lain. Apabila keluarga dapat melaksanakan tugas keluarga dalam bidang kesehatan dengan baik maka pasien hipertensi dapat mengontrol tekanan darah dalam batas normal sehingga tidak menimbulkan komplikasi.

\section{Activity Daily Living pada Lansia dengan Komplikasi Hipertensi di Posyandu Lansia di Desa Banjarejo Kecamatan Rejoso Kabupaten Nganjuk}

Hasil penelitian dari 37 responden, sebagian besar yaitu 20 responden $(54,1 \% \%) \quad$ memeiliki kategori ketergantungan ringan. Dari 20 responden yang memiliki kategori ketergantungan ringan pada komplikasi hipertensi, hampir setengahnya yaitu 17 responden $(45,9 \%)$ memiliki komplikasi masalah mata. Hasil dari uji chi-squaredidapatkan $\rho$ value $=$ 0,002 sehingga activity daily living di pengaruhi oleh komplikasi hipertensi yang diderita oleh lansia.

Menurut padila (2013), menjadi tua ditandai oleh kemunduran biologis yang terlihat sebagai gejala-gejala kemunduran fisik, salah satunya adalah pendengaran atau penglihatan mulai berkurang. Menurut Mujahidullah (2012) dan Wallae (2007), beberapa perubahan yang akan terjadi pada lansia diantaranya adalah perubahan fisik. Salah satu perubahan fisik yang dialami lansia adalah penurunan kekuatan otot yang disebabkan oleh penurunan masa otot (atropi otot), ukuran otot mengecil dan penurunan masa otot lebih banyak terjadi pada ekstermitas bawah, sehinggan menghambat aktivitas sehari-hari pada lansia. Lansia yang mengalami Komplikasi hipertensi mengakibatkan sebagian besar lansia bergantung pada keluarga, sehingga mengakibatkan kurangnya aktivitas pada lansia. Aktivitas fisik sangat penting perannya terutama bagi lansia. Namun, karena keterbatasan fisik yang dimiliki lansia akibat pertambahan usia serta perubahan dan penurunan fungsi fisologis, maka lansia memerlukan beberapa 
penyesuaian dalam melakukan aktivitas fisik sehari-hari (Fatimah, 2010).

Pada penelitian ini dapat disimpulkan bahwa terjadi hubungan activity daily living pada lansia dengan komplikasi hipertensi. Penelitian ini sejalan dengan penelitian yang dilakukan Parunta dan Rumagit (2015) yaitu ada hubungan yang bermakna antara aktivitas fisik dengan tekanan darah pada lansia. Pasien dengan komplikasi hipertensi seharusnya tetap melakukan pekerjaan tetapi selalu dalam pengawasan keluarganya.

\section{Dukungan Keluarga dengan} Activity Daily Living pada Lansia dengan Komplikasi Hipertensi di Posyandu Lansia di Desa Banjarejo Kecamatan Rejoso Kabupaten Nganjuk

Hasil uji sparmanrank di dapatkan $p$ value $=0,000 \leq \alpha=0.05$ maka Ha ditreima dan nilai $\mathrm{r}=0,598$ yang artinya tingkat hubungan sedang sehingga ada hubungan antara dukungan kelurga dengan Activity Daily Living pada lansia dengan komplikasi hipertensi di posyandu lansia di desa banjarejo kecamatan rejoso kabupaten nganjuk.

Faktor yang mempengaruhi dukungan keluarga menurut (Purmawan dan Rahayu, 2015) Faktor internal berasal dari individu itu sendiri meliputi faktor tahap perkembangan yaitu pemahaman dan respon terhadap perubahan kesehatan yang berbeda-beda pada setiap rentang usia (bayi-lansia). Selanjutnya adalah faktor pendidikan atau tingkat pengetahuan. Dalam hal ini kemampuan kognitif yang membentuk cara berfikir seseorang termasuk kemampuan untuk memahami faktor faktor yang berhubungan dengan penyakit dalam upaya menjaga kesehatan dirinya. Selanjutnya adalah faktor eksternal berasal dari luar individu itu sendiri dan terdiri dari tiga hal. Pertama, praktik di keluarga yaitu cara keluarga memberikan dukungan yang mempengaruhi penderita dalam melaksanakan kesehatannya secara optimal.Penggunaan sistem dukungan keluarga yang terdiri dari dukungan informasional, dukungan penilaian, dukungan instrumental dan dukungan emosional yang merupakan suatu bagian integral dari keseluruhan dukungan yang berpusat pada suatu pendekatan keluarga akan meningkatkan kesehatan dan adaptasi mereka dalam kehidupan. Secara lebih spesifik, keadaan dukungan sosial yang adekuat terbukti berhubungan dengan menurunnya tingkat mortalitas (tingkat kematian) serta lebih mudah sembuh dari keadaan sakit, fungsi kognitif, fisik dan kesehatan emosi. Pemberdayaan pada pasien penderita strokediharapkan mendapat dukungan yang penuh 
terutamapada dukungan keluarga

(Friedman, 1998 dalam sendi 2015).

Pasien dengan komplikasi hipertensi sering mengalami kelemahan fisik dan kurang memiliki kemampuan aktivitas pada salah satu bagian dari anggota tubuh dalam pemenuhan ADL harus memerlukan bantuan orang lain. Untuk mempercepat pemulihan diperlukan pengobatan yang relatif lama sehingga motivasi maupun dukungan agar tidak cepat putus asa dari keluarga atau orang sekitar sangat berpengaruh dalam proses pemulihan ( Arianti,2009).

Berdasarkan fakta dan teori diatas peneliti berpendapat bahwa ada hubungan antara dukungan keluarga dengan Activity Daily Living pada pasien komplikasi hipertensi. Semakin baik dukungan keluarga maka semakin baik pasien melakukan pemenuhan Activity Daily Living. Peran perawat dalam pemenuhan ADL sebagai Peran perawat edukator yaitu memberikan informasi mengenai dukungan keluarga yang baik dalam perawatan lansia dengan komplikasi hipertensi agar selalu mengikutsertakan pasien dalam segala tindakan yang dilakukan setiap hari.

\section{KESIMPULAN}

Dukungan keluarga pada lansia dengan komplikasi hipertensi di Posyandu
Lansia di Desa Banjarejo Kecamatan Rejoso Kabupaten Nganjuk dari 37 responden hampir setengahnya dengan kategori cukup yaitu 15 responden (40,5\%).Activity daily living pada pada lansia dengan komplikasi hipertensi di Posyandu Lansia di Desa Banjarejo Kecamatan Rejoso Kabupaten Nganjuk dari 37 responden sebagian besar activity daily living pada lansia dengan kategori ketergantungan ringan yaitu 20 responden (54,1\%).Ada hubungan dukungan keluarga dengan activity daily living pada lansia dengan komplikasi hipertensi di Posyandu Lansia di Desa Banjarejo Kecamatan Rejoso Kabupaten Nganjuk $\rho$ value = $0,000 \leq \alpha=0,05 r=0,598$.

Bagi institusi perlu memasukan materi dukungan keluarga dalam setiap mata kuliah khusunya dalam pemenuhan Activity Daily Living pada lansia dengan hipertensi.

\section{DAFTAR PUSTAKA}

Aisyah. 2011. Perkembangan Sosial Emosional dan Kepribadian. Jakarta: Universitas Terbuka.

Elfrianti,P,. 2016. Hubungan Dukungan Keluarga dengan Tingkat Kepatuhan diet Lansia dengan Hipertensi di Lingkungan Kelurahan Tonja. 2016. Jurnal keperawatan (online). (http://eprints.kemenkes.ac.id.,) [ Diakses tanggal 16 Mei 2018. jam 13.00] 
Fatimah (2010). Gizi Usia Lanjut. Jakarta : Erlangga

Friedman,M.M. 1998, Keperawatan Keluarga : Teori, dan Praktek. Jakarta : EGC

2016. Masalah hipertensi

di indonesia. Diperoleh dari www.depkes.go.id

Mujahidullah, Khalid. 2012. Keperawatan gerontik. Jogjakarta : Pustaka Pelajar

Nursalam. (2016). Konsep Dasar Penerapan Metodelogi Penelitian Ilmu Keperawatan. (S. Medika, Penyunt.) Jakarta

Oram,B. (2010) ,Total Dissolved Solids. (Diakses 25 maret 2018) dari http://www.water-

research.net/totaldissolvedsolids.html

Osamor, P. A. (2015). Social Support and Management Of Hypertension In SoutWest Nigeria. Crdiovascular Journal Of Africa. Vol 26(1), 29-33. Diunduh [ Tanggal 1 Juli 2017 ] dari https://www.ncbi.nih.gov/pmc/articles/ PMC4392208/

Padila. 2013 , Asuhan Keperawatan Penyakit Dalam. YOgyakarta : Nuha Medika

Setiadi. (2007). Konsep dan Praktek Penulisan Riset Keperawatan, Edisi 2. Yogyakarta. Graha Ilmu.

Sinaga A. (2015). Hubungan Dukungan Keluarga Dengan Pencegahan Hipertensi Pada Lansia Di Desa Sukamaju Wilayah UPTD Cikalong Kecamatan Cimaung. Jurnal Stikes Santo Borromeus. (Diakses 15 Maret 2018).

Tamher, S. \& Noorkasiani. 2009. Kesehatan Usia Lanjut dengan Pendekatan Asuhan Keperawatan. Jakarta : Salemba Medika 